\title{
The Impact of Type 2 Diabetes on Periodontal Health in Elderly Subjects: Princeps Study
}

\author{
Abrar-Ahmad Zulfiqar, M.D, MSc ${ }^{1 *}$, Jean Doucet, M.D, Ph.D ${ }^{2}$ and Hervé Moizan, Ph.D ${ }^{3}$ \\ ${ }^{1}$ Department of Geriatrics, Saint-Julien Hospital, University Hospital of Rouen, 76141 Le Petit Quevilly, France \\ ${ }^{2}$ Department of Internal Medicine-Geriatrics-Therapeutics, Saint-Julien Hospital, University Hospital of Rouen, 76141 Le Petit Quevilly, France \\ ${ }^{3}$ Dentist Unit, Saint-Julien Hospital, University Hospital of Rouen, 76141 Le Petit Quevilly, France
}

${ }^{*}$ Corresponding author: Zulfiqar Abrar-Ahmad, M.D, MSc, Departement of Geriatrics, Saint-Julien Hospital, University Hospital of Rouen, 76141 Le Petit Quevilly, France; Email: abzulfiqar@gmail.com

Received: November 10, 2018; Accepted: November 25, 2018; Published: December 04, 2018;

\begin{abstract}
Very few studies have been done on oral health in the elderly and in particular the impact of type 2 diabetes on the dental appliance in the elderly. This is a feasibility study, with the use of a questionnaire, conducted in consultation with geriatric physicians, diabetologists and dentists.
\end{abstract}

Keywords: Periodontal Health, Type 2 diabetes, Elderly, Nursing Homes

\section{Letter to the Editor}

In 2014, an international project entitled "Factors Influencing the Oral Health of Elderly Diabetics 65 Years of Age and Older" was born. It is the fruit of collaboration between the University Hospital of Rouen in France and the University of Fortaleza in Brazil. The goal of the project was to deepen and broaden our current understanding of Type 2 Diabetes, and to evaluate the factors influencing the oral condition of elderly diabetics over 65 years of age.

It was an epidemiological study, prospective and noninterventional, carried out over a period of 9 months, between March 2014 and November 2015 at the Saint-Julien site at the University Hospital of Rouen, France.

The subjects were 78 patients with type 2 diabetes, predominantly males (43 subjects, 55.1\%), with an average age of $80.8+/-8.0$ years $(80.7+/-8.1$ for the females, $80.9+/$ - for the men), with the extremes in age being 65 and 98 , and a median age of 81 . There are no significant differences between the control of diabetes and variables like age, gender, BMI, tobacco use and prosthetic parameters. A trend is apparent between inclusion links and poor glycemic control ( $\mathrm{p}=0.07$ ) variables: $80 \%$ of patients in nursing homes are poorly controlled versus only $46.2 \%$ of home patients. $62 \%$ of patients presenting an $\mathrm{HbA} 1 \mathrm{c}<=7.5 \%$ have more than 4 Functional Units (FUs), versus $47 \%$ of patients with poor glycemic control. We observe that a higher percentage of poorly controlled patients do not present a functional pair (32\% versus $17 \%$ of controlled subjects). Out of 59 patients with teeth, we have 16 patients with a partial set of teeth whose HbAlc is unknown, 24 with teeth and an $\mathrm{HbAlc}<=7.5 \%$, and 19 with teeth and an HbAlc $>7.5 \%$. We observe that sextant scores $3, \mathrm{X}$ and 2 occur primarily among those patients with an $\mathrm{HbAlc}<=7.5 \%$, representing respectively $31.25 \%, 27.08 \%$ and $24.31 \%$ of total sextants. These correspond to testing $<3 \mathrm{~mm}$ (score 2); from 3.5 to $5.5 \mathrm{~mm}$ (score 3) or sextants with either 0 teeth or 1 tooth. Diabetic patients with poorly controlled diabetes $(>7.5 \%)$ predominantly present a score of X (44.74\%), followed by scores of 3 (21.93\%) and 2 (18.42\%). A score of 4 , representing the most advanced conditions of poor periodontal health, is found in $6.25 \%$ of controlled patients, versus $9.65 \%$ of poorly controlled patients. Out of 42 diabetic patients with teeth, only 9 patients present a plaque index $<25 \%$. The average plaque index for those patients presenting an $\mathrm{HbAl} c<=7.5 \%$ is $58.12 \%$, versus $69.10 \%$ for those patients with an HbAlc $>7.5 \%$.

This indicates that the majority of sextants examined that present a score of 0 or 1 occur in controlled diabetic patients $(11.1 \%$ versus $5.2 \%)$. A score of 4 , representing the most advanced periodontal disease, is primarily found in poorly controlled diabetic patients $(9.5 \%$ versus $6.2 \%$ ). However, there is a wider gap between the two controlled versus poorly controlled groups in the number of edentulous sextants (score $\mathrm{X}$ ), which consequently influences the number of functional units and the Masticatory Coefficient $(M C)(p=0.0011)$. Many studies have reported high numbers of missing teeth among diabetic patients, but in most cases the accounts show that the difference observed is not significant [1].

In the case of Functional Units (FU) number $<=4$, with a majority of sextants edentulous (non rehabilitated) is discernable (60\%), while in more balanced dental situations (FU>4) the sextants with teeth presenting scores of 2 and 3 are more common $(26.2 \%$ and $40.4 \%$ respectively). Similarly, situations in which $\mathrm{CM}>40$ are primarily present in edentulous sextants $(46.2 \%)$, versus sextants presenting scores of 2 and $3(27.7 \%$ and $51.1 \%$ respectively) for situations in which $\mathrm{CM}>=40$.

Conservation of a minimum of 20 teeth is necessary in order to maintain proper masticatory function. However, in our group, over $3 / 4$ of patients have fewer than 20 teeth in their mouths [2]. We observe 
a weak masticatory coefficient among our type 2 diabetic patients with teeth. $89 \%$ of patients have a masticatory coefficient under 60 , and it is exacerbated among the poorly controlled patients. However the lower masticatory coefficient and low number of remaining teeth could be related to undernourishment or malnutrition [3-4]. Evaluation of the group of patients with teeth shows a clear prosthetic need among elderly diabetics. 50.8\% of these patients need maxillary and/or mandibular rehabilitation, either due to a complete lack of rehabilitation or to an inadequate prosthesis or prostheses.

This is an ongoing study.

\section{Reference}

1. Taylor Gw, Manz MC, Borgnakke WS (2004) Diabetes, periodontal diseases, dental caries, and tooth loss : a review of the literature. Comprend Contin Educ Dent 25: 179-184, 186-188, 190 [crossref]

2. Krall E, Hayes C, Garcia R (1998) How dentition status and masticatory function affect nutrient intake. J Am Dent Assoc 129: 1261-1269 [crossref]

3. Ervin RB, Dye BA (2012) Number of natural and prosthetic teeth impact nutrient intakes of older adults in the United States. Gerodontology 29: 693702 [crossref]

4. Savoca MR, Arcury TA, Leng X, Chen H, Bell RA, et al (2010) Severe tooth loss in older adults as a key indicator of compromised dietary quality. Public Health Nutr 13: 466-474 [crossref]

\section{Citation:}

Zulfiqar AA, Doucet J, Moizan H (2018) The Impact of Type 2 Diabetes on Periodontal Health in Elderly Subjects: Princeps Study. Endocrinol Diabetes Metab J Volume 2(4): 1-2. 